\title{
AS POLÍTICAS PÚBLICAS DE PRESERVAÇÃO E TOMBAMENTOS DOS ESPAÇOS: BREVE GENEALOGIA DA LEGISLAÇÃO PATRIMONIAL DE ANÁPOLIS.
}

\section{THE PUBLIC POLICIES OF PRESERVATION AND LANDFILLS: BRIEF GENEALOGY OF THE PATRIMONIAL LEGISLATION OF ANÁPOLIS.}

Éder Mendes de Paula ${ }^{1}$ Murillo Oliveira Soares ${ }^{1}$

Resumo: Ao longo do século XX vimos um crescimento na gestão dos patrimônios públicos no mundo ocidental, tais medidas tiveram como ideia garantir a sobrevivência das culturas e suas produções patrimoniais, porém o Brasil caminhou de forma mais lenta para essa concepção, em Anápolis tal processo se manteve de forma mais lenta ainda. Neste artigo proponho uma genealogia sobre as leis de tombamentos do município de Anápolis e como essas leis foram focadas em um setor público e privado detentor de uma memória e poder local.

Palavras-chaves: Anápolis, patrimônio, arquitetura, leis de tombamentos, memória, história de Goiás

\begin{abstract}
Throughout the 20th century we saw a growth in the management of public assets in the Western world, such measures had the idea of guaranteeing the survival of crops and their patrimonial productions, but Brazil walked more slowly towards this conception, in Annapolis such a process has remained slower still. In this article I propose a genealogy on the fallback laws of the municipality of Anápolis and how these laws were focused on a public and private sector that has a memory and local power.
\end{abstract}

Keywords: Anápolis, heritage, architecture, laws of tipping, memory, history of Goiás

\section{Introdução.}

Este artigo tem como intuito, analisar as políticas ao longo das décadas de tombamentos e preservação dos patrimônios da cidade de Anápolis.

Apesar da cidade possuir uma riqueza em termos de história e locais de memória, ela conta apenas com nove espaços considerados patrimônios municipais, tais espaços apresentam singularidades entre eles que por forças políticas os transformaram em espaços da história local.

Porém devemos vislumbrar que existem poucos espaços além da reestruturação urbana da cidade em 1930 que são reconhecidos como espaço do patrimônio local, ou espaço de outros tempos que foram reconhecidos, isso se deve pela falta da vontade política e econômica da cidade.

\section{Patrimônio e o efeito da memória em}

\section{Anápolis.}

Anápolis se emancipou como cidade no dia 31 de julho de 1907, desde a sua formação se pautou em desenvolver uma autonomia econômica baseada na agricultura, porém com o seu crescimento urbano e econômico despertou a chegada da linha férrea na década de 1930, de lá para cá, viu uma reestruturação urbana em seu meio social.

Com a chegada da ferrovia em 1935, acentuou um projeto de modernização, a cidade e os seus espaços, projetando a suas estruturas sociais, culturais e econômicas para a modernidade pulsante na década de 1930 no Brasil e em Goiás.

${ }^{1}$ Doutor em História pela Universidade Federal de Goiás. Professor do curso de Direito da Faculdade Evangélica de Goianésia.conversecomoeder@hotmail.com

${ }^{2}$ Mestrando em História pela Universidade Federal de Goiás, com ênfase em História das Cidades e Patrimônio. 
O projeto de modernidade, pautado em uma cidade voltada para a sua estruturação do trabalho e do capital, este projeto de modernidade deveria atender aos interesses dos grupos políticos e sociais da época, dessa forma o novo não deixaria espaço para as relações rurais e culturais anteriores a década dos anos 30 .

Dessa forma Anápolis foi aos poucos apagando os vestígios da sua história, deletando a sua memória rural, para dar espaço à uma cidade moderna e urbanizada, que atendia aos anseios dos "novos tempos".

Assim ao olharmos os patrimônios da cidade, percebemos uma falta de normatização, de vontade política ou interesse pelos próprios cidadãos.

Sabemos que o conceito de patrimônio é um terreno complexo e que abre margens para discussões amplas, sobre a sua importância, coerência e vontade dos envolvidos para efetivamente pensar e conservar tais patrimônios.

Assim, devemos pensar o que de fato seria o patrimônio? Quais as vantagens em se manter locais tombados para a comunidade? Anápolis realmente desejou manter espaços de memória?

Não devemos ter a pretensão de sermos exatos nas respostas, mas em abrir a discussão para os efeitos que a cidade deixou para nós ao longo de sua história.

\section{Estado e a patrimonialização.}

No Brasil o Estado sempre teve papel decisivo sobre as normas e formas de patrimônio, as forças sociais e culturais, sempre se envolveram para decidir o que de fato é importante ou não, o que deve ser mantido como memória e o que deve ser relegado ao esquecimento.

A palavra patrimônio estaria associada à noção do sagrado ou à noção de herança, de memória do indivíduo, de bens de família, principalmente no que diz respeito ao mundo antigo, aos monumentos da Antiguidade clássica, seria associado aos valores de posse, herança, segundo Santos (2001).

O patrimônio poderia ser entendido como bens materiais ou imateriais, escolhidos em uma infinidade de produções culturais humanas, tanto do passado como do presente. Sendo atribuídos valores estéticos, históricos, artísticos, paisagísticos, etnográficos, culinários, etc. Assim o patrimônio é tangenciado como testemunho de um povo, cultura, sendo evidenciado com valor de herança cultural, que ao serem selecionados transem em sua carga valor de herança para as futuras gerações.

A ideia de objetos considerados patrimônios, podem ser variados conforme $\mathrm{O}$ tempo e o espaço em que são pensadas as memórias, cada sociedade pensa e estabelece para si, o que deve ou não ser preservados, em síntese, o Estado teria o papel junto com a sociedade de estabelecer leis, projetos, que busquem resgatar, preservar e proteger os bens tombados.

Em 1931, ocorreu a maior institucionalização sobre patrimônio cultural e histórico da humanidade com a primeira reunião internacional sobre os valores e o papel que os arquitetos teriam sobre a esfera da preservação do patrimônio, com as cartas de Atenas.

A ideia da reunião era pensar os aspectos legais, os técnico-construtivos e os princípios 
norteadores da ação de conservação, o documento trazia em seu conteúdo a preocupação sobre as legislações e as garantias dos direitos coletivos sobre os individuais, propondo um fortalecimento dos Estados perante a preservação e conservação dos bens patrimoniais.

O Brasil o processo de patrimonialização dos bens materiais se iniciou na década de 1930 com o governo de Getúlio Vargas, com o projeto de manter e preservar a memória nacional e garantir a unicidade da identidade brasileira.

Em 1937 foi criado o Serviço do Patrimônio Histórico e Artístico Nacional, que tinha como função o tombamento, a preservação e conservação dos monumentos históricos, sobre tudo a agência possuía em seu corpo técnico o predomínio dos arquitetos, que focaram na preservação em grande maioria dos prédios arquitetônicos do período colonial do Brasil.

Podemos assim, pensar que os valores patrimoniais da época estavam voltados para os feitos de uma elite agrária, que havia dominado por longos períodos a história econômica e social do Brasil.

Mas ao olharmos para o Estado de Goiás, a realidade do discurso era outra, o Estado tentava afastar o "estigma" de local atrasado, rural e agrário, nesta década de 1930, o interventor do estado, Pedro Ludovico Teixeira, tinha outros planos, elevar o estado aos moldes econômicos da época.

Dessa forma, a construção de Goiânia, cidade planejada aos moldes da arquitetura francesa do art dèco, fugia aos assuntos do patrimônio colonial do Brasil, Goiás se projetava pela marcha para o oeste, o domínio do homem sobre a natureza.

Anápolis, pela sua proximidade com a nova capital, também tentava acompanhar os rumos que a nova política se propunha, com a chegada dos trilhos de ferro em 1935, com os trilhos trazia o discurso do moderno, do novo.

Uma série de mudanças foram implementadas no centro da cidade, um efeito cirúrgico urbano foi sendo colocado como um projeto de reestruturação e modernização da urbe pelo efeito da estrada de ferro.

A implantação da estrada de ferro, junto à colina histórica, foi fator determinante nessa instalação de depósitos, armazéns e indústrias de beneficiamento na área urbana, em todo o processo de crescimento da cidade. Com isso consolidou-se a posição de Anápolis como principal entreposto comercial do estado de Goiás. (FARIA E PEREIRA, 1976 p.28)

Como afirma Hobsbawm (1991 p.612) "a ferrovia representava a modernidade, a grande obra do capitalismo". E é graças à ferrovia que a modernização da cidade de Anápolis se tornou possível, mas essa modernidade não trouxe consigo nenhuma política de preservação dos monumentos arquitetônicos do período colonial.

O centro da cidade havia em sua grande maioria casas no estilo colonial, traço marcado pela produção econômica do algodão, café e cereais que moviam a economia local, a ideia de desenvolvimento da cidade não criou uma relação entre cultura de preservação e desenvolvimento financeiro. 
A movimento de modernização da cidade, procurou por meios das elites políticas e econômicas, apagar os traços rurais que haviam na cidade, as fachadas das casas passaram por reordenação para o estilo art dèco ou neoclássico.

Muitos proprietários
attendendo ao justo pedido
da nossa prefeitura
começaram a reforma e
pintura de seus prédios, afim
de que os nossos visitantes,
por ocasião da inauguração
da estação de ferro,
encontrem a cidade digna do
nome e do progresso de
Annapolis. (Jornal Annapolis
Sport Club- maio de 1935)
da época, João Luiz de

O prefeito da época, João Luiz de

Oliveira, decretou uma série de medidas, para transformar a cidade, no dia da inauguração da estação de ferro Goiás, a prefeitura coube o papel de limpar a cidade e dar boas-vindas ao "progresso": “(...) os prédios e muros completamente asseiados na parte central da urbs". (Jornal de Anápolis. 15/09/1935).

Desde o momento da sua reestruturação urbana, Anápolis renegou a sua própria memória, os agentes do Estado e das elites comerciais, não gostavam dos aspectos rurais da cidade, essa medida se manteve como política até os nossos dias, temos dificuldades em vislumbrar políticas de preservação e conservação dos patrimônios da cidade, mesmo com os tombamentos ao longo das últimas décadas.

Segundo Polonial (2007), Anápolis possui uma arquitetura em estilo "Art Déco" que merece ser preservada, pois retrata a mudança de cidade interiorana, pacata, para uma cidade moderna. Entretanto, o Município possui apenas nove monumentos tombados como patrimônios históricos.

A cidade não se desenvolveu para a área do turismo, mas para o setor industrial e de serviços, talvez este fato poderia ser usado como justificativa para a falta de empenho do setor público em criar medidas de patrimonialização da cidade, claro que não podemos relegar apenas ao poder público a obrigação em preservar, a própria população deve ter empenho e reconhecimento dos seus valores culturais e de memória.

$\mathrm{Na}$ década de 1970, o designer Aloísio Magalhães, trouxe uma nova visão sobre $\mathrm{O}$ tombamento no Brasil, os bens culturais passaram a ser entendidos não apenas como documentos de identidade da nação, mas elementos da cultura móvel como artesanatos, hábitos, as atividades das comunidades, essa abertura contribuiu para a ampliação sobre a ideia de patrimônio cultural na constituição de 1988.

Vários estados e municípios adotaram essa ampliação da ideia de patrimônio, em Anápolis foi feito o primeiro decreto legislativo, pela lei $\mathrm{n}^{\mathrm{o}} 513 / 75$, definindo o fórum da cidade localizado na Praça Bom Jesus, que já foi sede da Prefeitura e abriga, atualmente, o Centro Cultural da Cidade, marcando o início das políticas públicas para conservação dos espaços públicos.

O segundo decreto foi no ano de 1984, que estabeleceu como parte do patrimônio da cidade o mercado municipal Carlos de Pina, que foi feito nos anos de $1940 \mathrm{com}$ arquitetura art déco, com a lei 025/84, neste decreto foi autorizado a criação de um órgão para registrar e gerenciar os movimentos de tombamentos da cidade. 
Os avanços para o tombamento na cidade, sempre tiveram passos lentos, o terceiro decreto de lei só sairia mais de uma década depois, com a lei n $\mathrm{n}^{\mathrm{o}} 1.824 / 91$, de 03 de janeiro de 1991, o decreto aumentava o número de prédios a serem tombados e integrados ao patrimônio da cidade.

Foram reconhecidos como patrimônios os prédios da antiga cadeia pública localizado na rua 14 de julho, a estação ferroviária localizada na Praça Americano do Brasil que havia sido criada com a reorganização da cidade em 1935, o antigo Fórum localizado na Praça Bom Jesus e o Museu na rua Coronel Batista.

Ao analisarmos estes três edifícios como patrimônios materiais da cidade, devemos pensar como já na década de 1990, a cidade se apresentava atrasada com os tombamentos, não havendo outros patrimônios de cultura imaterial que fossem pensados como marco da cultura local, apenas prédios com valores econômicos ou políticos para a cidade.

A cadeia pública foi tombada como reforço do poder militar do Estado, sendo uma forma de tradição para tombamentos de patrimônios nas cidades em Goiás, como Pirenópolis e Cidade de Goiás, ambas as cadeias públicas dessas cidades foram tombadas e receberam investimentos do IPHAN (instituto do patrimônio histórico e artístico nacional), em Anápolis a patrimonialização foi feita como medida de preservação do prédio em estilo art déco.

A estação ferroviária marcou a chegada da modernização e dinamização da economia anapolina, integrando a cidade ao modo econômico que vigorava no país, com isso um avanço nos ares urbanos e a sua reestruturação, a sua patrimonialização foi um processo longo na justiça para que fosse efetivado o local como espaço de preservação, porém o que queremos analisar é outro aspecto.

O tombamento da estação reforça o caráter político e econômico para as políticas de tombamento, visto que a estação foi um local de grande mobilização da cidade nas esferas de desenvolvimento econômico pelas elites do café e algodão, que se mantiveram até as décadas de 1940 e 1950, quando os trilhos da estação foram retirados e a estação desativada.

Outro local que recebeu o tombamento municipal foi o prédio do fórum da cidade, localizado na Praça Bom Jesus no coração da cidade, o fórum representa em todas as sociedades ocidentais aspectos de poder do Estado perante a população, os edifícios são construídos com estilos e alturas de certa forma avantajados, para mostrar o poder e a força estatal:

O edifício público é uma testemunha da vida de um povo, um documento escrito no tempo. Não se limita à finalidade imediata do serviço do Estado. É, por certo, um memorial da civilização que o informa. A época que não se assinala pela arquitetura, significação e valor de suas construções, sobretudo em matéria de edifícios públicos, é um tempo que nada revelou de novo, uma geração que 
não conseguiu confiar a sua mensagem ao porvir, uma comunidade que não soube perpetuar-se através do eloquente simbolismo dos monumentos levantados pelo esforço coletivo. (SEGAWA, 2008)

Com as suas linhas e formas arquitetônicas do estilo art dèco que vigorou no Brasil, incluindo em Goiânia, o prédio é uma marca da força do poder político e da justiça do Estado, assim foi valorizado pela política de tombamento, forças que decidem sobre os monumentos que devem ser patrimonializados, atualmente abriga a casa de cultura da cidade.

Neste mesmo decreto de 1991, sobre os tombamentos dos prédios públicos, temos um em especial que marcar o local como função social e histórica da cidade o Museu Alderico Borges de Carvalho.

O local foi decretado em 1971 como museu, anteriormente a casa pertencia ao coronel Zeca Batista, antes do município ser elevado à vila, o local marca um período importante da história da cidade, pelos feitos dos agentes políticos que lutaram para transformar a pequena freguesia em vila no ano de 1887.

O coronel Zeca Batista foi um dos habitantes mais antigos da cidade e ex-prefeito de Vila de Santana, antigo nome do município de Anápolis, relatos afirmam que o coronel gozava de grande prestígio entre as elites goianas.

A transformação da sua casa em museu e depois em patrimônio, mostram as relações que o poder público mantêm para preservar e escolher os locais de memória e os personagens que devem ficar na história local.

Ao transformar o próprio museu em local de memória, podemos trazer que os objetos em seu local trazem para si o esquecimento, pois os fatos, outros habitantes foram esquecidos pela patrimonialização, ao eleger tal local como fruto de uma materialidade e selecionando objetos para a memória, outros espaços e objetos são esquecidos ou não dados o devido valor.

A quarta lei foi aprovada em 04 de dezembro de 1992, a Lei 2.058/92, que autorizava a criação da Fundação de Esportes e Cultura, seria criada na antiga sede da prefeitura e fórum no centro da cidade, foi inaugurado o centro de cultura de Anápolis - Ulisses Guimaraes.

Já nos anos 2000 houveram grandes avanços na política de tombamentos da cidade, o próprio IPHAN ganhou grande autonomia com o decreto de lei 3.551, em 4 de agosto de 2000, ampliando a atuação do Instituto para o território brasileiro.

O decreto abriu a discussão para os tombamentos de caráter materiais e imateriais, como forma de valorização das diversas culturas nacionais.

Em Anápolis ao longo da década de 2000, foram aprovadas mais quatros leis, que tombaram mais cinco prédios, porém não ampliou a discussão para os bens imateriais, discussão amplamente debatida pelas esferas públicas e políticos sobre patrimônio do Brasil.

Foram tombados em 05/04/2001 com a Lei Municipal no 2.725, o coreto da Praça James Fanstone, o coreto foi criado na década de 1930, 
em estilo neoclássico, para fazer jus ao grande hospital que se instalava ali, o primeiro hospital do Estado de Goiás, o hospital Evangélico de Goiás que foi construído pelo médico inglês James Fanstone em 1927.

O edifício possuía grandes recursos tecnológicos para à época, sendo um prédio de seis andares, considerado na época como o maior e mais moderno do estado naquele período.

Nesse prédio, um verdadeiro
assombro, um incalculável
avanço, para a época, pois foi
o primeiro prédio 'de tantos
andares' construído no
Estado de Goiás, passaram a
funcionar o consultório,
laboratório e quase todas as
dependências médicas do
hospital. (FERREIRA 1979
p.191)

Depois em 28/04/2003 pelo decreto de Lei Municipal n' 2.952, foi tombado a "Casa JK", o local onde hoje se localiza o aeroporto de cargas da cidade, foi usado pelo presidente da república Juscelino Kubitschek em 1956, para dar início às obras da construção de Brasília.

Atualmente o local está abandonado e sem uso para a população local, caso não exista um projeto que revitalize o local, com certeza o tempo deve destruí-lo, porém qual o objetivo de tombar tal local e não dar sentido de uso?

A importância do local se deve pela importância que Anápolis desempenhou para a construção da nova capital, porém um espaço sem finalidade de uso, não serve para a memória local.

Outro decreto de lei foi promulgado em 07/12/2005 tombando os edifícios do Colégio Antesina Santana, o local foi no final do século XIX a antiga cadeia pública da cidade, porém com a reestruturação urbana foi demolido e construído o colégio em estilo art dèco.

Outro edifício tombado foi do colégio Couto Magalhães, construído em 1932, para o ensino de crianças da cidade em especial as evangélicas da cidade, o prédio feito em estilo art dèco, mantem grande parte da sua estrutura original, a escola estabelecia uma forte ligação com os agentes políticos da época de 1930, pois estava sobre o mesmo grupo político e econômico que construíram o Hospital Evangélico de Goiás, onde houve o tombamento do coreto James Fanstone.

$\mathrm{O}$ último decreto de Lei Municipal $\mathrm{n}^{\circ}$ 3.230, foi em 2007 com o tombamento da Fonte Luminosa da Praça Bom Jesus, atualmente a praça não contém muitas características originais, o centro da cidade vem passando pelos últimos anos por uma forte transformação no seu centro urbano.

$\mathrm{O}$ que podemos perceber ao longo das décadas é que todos os locais escolhidos para os tombamentos municipais se localizam em grande maioria nas décadas de 1930 e 1940 e estão no centro da cidade, assim o estudo e as políticas devem ser ampliadas para outras áreas da cidade.

Segundo o historiador Juscelino Polonial (2007), outros espaços devem ser contemplados pela memória, como a estação Engenheiro Castilho, localizado no bairro Jundiaí, o prédio foi inaugurado no ano de 1951, havia abrigado parte da prefeitura da cidade, o prédio possuí uma arquitetura em estilo art dèco, e guarda momentos importantes da cidade local, como o golpe militar na cidade. 
Além de outros espaços na cidade que podem acrescentar a história da cidade, ainda existe uma falha gigantesca com relação as outras produções de cultura como o folclore, as danças, as festas, as manifestações religiosas, a culinária.

Quando analisamos os objetos tombados percebemos uma clara escolha dos bens que dizem aos valores arquitetônicos europeus, em grande maioria dos prédios que foram tombados apresentam características dos estilos francês do art dèco e neoclássico, trazidos para o Brasil nas décadas de 1930.

Não estamos fazendo um julgamento quanto os tombamentos, mas um questionamento sobre os motivos que deixaram de fora outros locais que ainda se encontram na cidade como os galpões de cerais que fizeram parte da história local, as casas em estilo colonial, os bens ambientais.

O que podemos perceber que é necessário um avanço quando as políticas de patrimonialização, um resgate da memória local para que a própria população consiga se ver representada em seus espaços de memória, uma ampliação sobre os estudos antropológicos e sociais quanto a cultura regional para um resgate amplo da memória e da história de Anápolis.

\section{Referências:}

CAMPOS, Edilberto Sebastião Dias. Estudo sobre legislação do patrimônio histórico e cultural do município de Anápolis- Goiás. In: MUSEU HISTÓRICO - Alderico Borges de Carvalho. Caderno de Pesquisas 2009. Secretaria Municipal da Cultura. Ano 1/No1, p. 42-47.

CANCLINI, N. G. O Patrimônio Cultural e a construção imaginária nacional. In: Revista do Patrimônio Histórico e Artístico Nacional, n. 23, p. 95-115. 1999.

CHIAROT'TI, Tiziano Mamede. Preservação do patrimônio histórico e cultural de Anápolis: dos Tombamentos à Lei $\mathrm{n}^{\circ}$. 2.936/2002. In: MUSEU HISTÓRICO - Alderico Borges de Carvalho. Caderno de Pesquisas 2013. Secretaria Municipal da Cultura. Ano 4 e $5 / n^{\circ} 1$ e 2, p. 29-37.

FARIA, Ivone Oliveira \& PEREIRA, Jacy C. de Azevedo. A formação da estrutura urbana. In. Correio do Planalto, Anápolis, 1976.

FONCESCA, Maria Cecília Londres. Patrimônio Cultural: por uma abordagem integrada (Considerações sobre materialidade e imaterialidade na prática da preservação). Caderno de Estudos do PEP. COPEDOC/IPHAN-RJ, 2007. p. $69-73$

HOBSBAWM, Eric J. A era das revoluções Burguesas: 1789-1848. 8 Edição, Rio de Janeiro, Paz e Terra, 1991.

POLONIAL, J.M. (org.). O Centenário: iniciação à história de Anápolis. Anápolis: AEE, 2007.

, Juscelino. Introdução à história política de Anápolis (1819-2007). Anápolis: Edição do Autor, 2007.

SEGAWA, H. Rumo à industrialização: arquitetura da primeira metade do século XX. In. UNESCO. Arquitetura na formação do Brasil. 2008. 